\title{
Palisading Necrosis
}

National Cancer Institute

\section{Source}

National Cancer Institute. Palisading Necrosis. NCI Thesaurus. Code C68752.

A morphologic appearance consisting of small, irregular regions of necrosis surrounded by dense accumulations of tumor cells; the tumor cells are more densely packed at the edge of the necrosis than in other regions of the tumor and thus appear to "palisade" around the necrotic zone. 